\title{
Operative Treatment of Mallet Fractures
}

\author{
Mohammed Anter Ali Abdelhameed ${ }^{1 *}$, Hossam Abubeih², Khaled M Mostafa ${ }^{2}$ and Gallal Z Said $^{2}$ \\ ${ }^{1}$ Department of Orthopedic Surgery and Traumatology, Faculty of Medicine, Assiut University, Egypt \\ ${ }^{2}$ Assiut University Hospital, Egypt
}

Submission: September 24, 2019; Published: October 16, 2019

*Corresponding author: Mohammed Anter Ali Abdelhameed, Department of Orthopedic Surgery and Traumatology, Faculty of Medicine, Assiut University, Egypt

\begin{abstract}
Mallet finger in adults is a traumatic lesion of the terminal extensor band in zone 1, and is characterized by intact skin and division of the tendon insertion alone (tendinous mallet) or an avulsion of less than one third of the articular surface of the distal phalanx (bony mallet) resulting in inability to actively extend the distal interphalangeal joint. When untreated, this can lead to osteoarthritis at the distal interphalangeal joint and, potentially, a swan-neck deformity. Although a wide variety of both open and percutaneous surgical techniques have been described for the treatment of mallet fractures, accurate anatomic reduction and stable fixation of mallet fractures remains one of the most challenging operations in hand surgery. Common problems with existing pin, wire or screw techniques include loss of reduction, recurrent subluxation, pin migration, wire cut-out and the common requirement for prolonged trans-articular K-wire splintage and consequent inability to initiate early motion of the distal interphalangeal joint.
\end{abstract}

Keywords: Mallet fractures; Block extension; Hook plates

\section{Introduction}

Mallet fractures are avulsion fractures of the distal phalangeal base including peri- or intraarticular fractures comprising the insertion of the extensor tendon. The disruption of the terminal extensor mechanism results in a characteristic flexion deformity of the distal interphalangeal joint. These injuries are commonly encountered in ball-related sports injuries from axial loading or a forceful flexion of the extended digit [1]. Neglecting this injury or incorrect treatment may lead to distal interphalangeal joint dysfunction which subsequently leads to either $1 \mathrm{~mm}$ lengthening of the terminal extensor tendon which in turn leads to 25 degrees of extension lag or $1 \mathrm{~mm}$ shortening of the terminal extensor tendon, severely restricting the distal interphalangeal joint flexion, also causing persistent pain and aesthetic disfigurement [2]. Extension lag at the distal interphalangeal joint becomes clinically evident when there is extensor tendon excursion of $3 \mathrm{~mm}$ or more. Bony mallet fingers can have an associated instability that can manifest as subluxation or dislocation. Biomechanical studies have shown that subluxation occurs consistently when greater than 52 percent of the articular surface is affected and rarely when fracture fragments measure less than 43 percent. When untreated, this can lead to osteoarthritis at the distal interphalangeal joint and, potentially, a swan-neck deformity [3].

A variety of both open and percutaneous surgical techniques have been described for the treatment of mallet fractures, but accurate anatomic reduction and stable fixation of mallet fractures remains one of the most challenging operations in hand surgery. Common problems with these techniques include loss of reduction, recurrent subluxation, pin migration, wire cutout and the common requirement for prolonged trans-articular K-wire splintage and consequent inability to initiate early motion of the distal interphalangeal joint [4-9].

\section{Surgical Anatomy of the Distal Interphalangeal Joint}

The anatomy of the distal phalanx is unique and complex. The normal range of motion at the distal interphalangeal joint (DIPJ) is between $0^{\circ}$ and $85^{\circ}$, although the functional flexion posture has been reported to be $39^{\circ}$ [10]. Substantial stability to the DIPJ is provided by the combination of the extensor and flexor tendons, a thick volar plate and stout collateral ligaments. The dorsal portion of the collateral ligaments provides rebound extension of the flexed DIPJ, protecting the joint from greater than $45^{\circ}$ of volar subluxation despite a complete disruption of the extensor tendon. The short lever arm of the DIPJ further contributes to its stability, as evidenced by the rarity of simple DIPJ dislocations [11,12].

Extension of a digit is complex in anatomy and function. It is a linkage system created by the extrinsic system and the intrinsic system. The extrinsic system, innervated by the radial nerve, extends the metacarpophalangeal joint and the interphalangeal joints. The intrinsic system is innervated by the ulnar and median nerves and is composed of four dorsal interossei, three palmar interossei and four lumbrical muscles. These muscles act to 
extend the proximal and distal interphalangeal joints and flex the metacarpophalangeal joint [13]. Injuries to the extensor tendons have been grouped into anatomic zones for easy understanding and classification. The most widely accepted classification is that of Verdan. This system defines eight zones, from zone I at the DIPJ level to zone VIII at the distal forearm level. The use of these zones is convenient for assessing injury patterns, repair techniques and rehabilitation. Zone I is the area of the distal phalanx and DIPJ. In this region, the conjoint extensor tendon is well defined and dorsally positioned. Injuries here disrupt the terminal extensor tendon. This laceration of the conjoint tendon results in a flexed posture of approximately 40 degrees at the DIPJ. Partial transection results in a lesser extension lag and a decrease in the strength of extension against resistance from a flexed position. The extension lag may increase if the partial injury is not treated appropriately. Due to flat profile of the extensor tendons in this area, there is increased surface area between the repaired tendon and surrounding soft tissue and thus more susceptible to adhesions [14].

\section{Epidemiology}

Mallet finger lesions are common, with a prevalence of $9.3 \%$ of all tendon and ligament lesions in the body and an incidence of $5.6 \%$ of all tendinous lesions in the hand and wrist. Globally, no gender difference is present in the affected population, although high-energy mechanisms of injury are more common in young males and low-energy mechanisms of injury are common in elderly females. All authors concur that the index and thumb fingers are the least frequently affected. However, some researchers have described the middle finger as the most affected, whereas others have identified the ring finger to be the most affected, and still others the little finger. The dominant hand is more often affected. Tendinous mallet finger is more common than bony mallet finger [15-17].

\section{Mechanism of Injury}

The process is divided into two steps by all researchers. The first step is the application of an axial force to the distal end of a straight finger. The second step varies among authors. Some have argued that the axial force is followed by extreme passive DIPJ hyperextension. This explains bony mallet injuries. Others have proposed that the axial force is followed by extreme passive DIPJ hyperflexion, which explains tendinous mallet fingers. Other researchers have suggested that the resistance of the oblique retinacular ligament fibers determine tendon or bone avulsion [18-20].

\section{Classification}

The three classifications of mallet finger are old and were presented by Wehbe [21] in 1984, Tubiana [22] in 1986, and Doyle [23] in 1993. They are all based on radiological assessments. None of these classifications corresponds to a consensus regarding the treatment algorithm, and all include growth plate fracture. The bone fragment sizes of $1 / 3,20 \%$, or
$50 \%$ of the articular surface are arbitrary and do not correspond to any pathophysiological data. Some authors have shown that dorsal fractures of the distal phalanx base become unstable if more than $48 \%$ of the joint surface is avulsed. However, clinical experience shows that subluxation can occur even in smaller avulsions. The percentage of the joint surface involved is therefore not the only factor involved in instability. Concomitant DIPJ volar plate lesions probably play a role in joint instability [24].

Tubiana's classification [22] describes four types of lesions. It considers the size of the bony fragment and subluxation. It includes tendinous mallet deformities and excludes open lesions and correlates bone fragment size with volar subluxation. Lesions are subcategorized according to the presence of a bony fragment larger than one third of the articular surface. Doyle's classification [23] describes six types of lesions. It considers the anatomical lesion and the size of the fractured bone fragment and includes tendinous mallet deformities and open lesions. It does not correlate bone fragment size with volar subluxation. The sizes of the bony fragment that determine the subtype are $20 \%$ and $50 \%$ of the articular surface. Wehbe and Schneider's classification [21] describes nine different possible lesions. It considers the anatomical lesion and the size of the fractured bone fragment, excluding tendinous mallet deformities and open lesions. It does not correlate bone fragment size with volar subluxation. Lesions are subcategorized according to the presence of a bony fragment larger than one third of the articular surface.

\section{Procedure}

\section{Non-operative Treatment of Mallet fractures}

Conservative treatments vary regarding the immobilization position, type of splint, and treatment duration. It is indicated for all tendinous mallet fingers and type IA Wehbe and Schneider bony mallet fingers [25]. Since biomechanical studies have demonstrated that PIPJ mobilization does not move the terminal extensor band, researchers no longer recommend PIPJ immobilization in the treatment of mallet finger [26]. The DIPJ immobilization position varies among different authors. Some have advocated hyperextension and others a straight immobilization. Hyperextension aims at bringing both tendons ends into contact to avoid healing with a lengthened callus. Ischemic skin lesions or, in bony mallet fingers, DIPJ subluxation can occur if DIPJ hyperextension is excessive. We advise moderate hyperextension immobilization for tendinous mallet injuries and straight immobilization for bony mallet injuries [27-30].

Numerous immobilization devices have been described, with a volar bearing, a dorsal bearing, or a combined dorsal and volar bearing. The drawbacks of a volar bearing are insufficient DIPJ hyperextension and pulp occlusion that is not usable during treatment. The main drawback of a dorsal or combined bearing 
is pressure on the tendon healing site with correspondingly elevated risks of skin maceration and nail dystrophy. In order to counter these complications, some authors have proposed a volar bearing on the middle phalanx combined with a glued dorsal splint on the nail to avoid pressure on the tendon healing site [31-33].

A consensus exists that immobilization for a tendinous mallet finger injury should last longer than for a bony mallet injury because tendon healing takes longer than bone healing. For bony mallet finger, treatment lasts between six and eight weeks, but most studies have recommended six weeks. For tendinous mallet finger, treatment lasts between six and eight weeks, but most studies have recommended eight weeks. After an initial phase of strict immobilization, many authors have proposed continuing treatment with a night splint for two to four weeks. A level I study has proven, however, wearing a night splint does not affect the outcome of treatment $[27,31,34,35]$. Poor patient compliance is the main drawback of conservative treatments. Despite explanations regarding the necessity of strictly wearing a splint for a prolonged period, some patients remove or reposition the splint or give up the treatment altogether. Patient cooperation is mandatory for obtaining good results. Some authors have described using a glued splint to address the issue of poor compliance $[28,36]$.

\section{Operative Treatment of Mallet fractures}

Surgical treatments vary regarding the approach, principle of reduction, and fixation equipment. The surgical approach can be open or percutaneous. An open approach has the advantage of providing direct access to the extensor tendon. The risks are skin necrosis, infection, nail dystrophy, osteoarthritis, and stiffness. These risks are reduced in a percutaneous approach, but this technique presents the risk of imperfect bone reduction [20]. Reduction and fixation of the displaced fragment can perform directly and/or indirectly. Direct methods include the trans-osseous suture of a tendinous mallet or of a small bony fragment [25] as well as fixation of a large bony fragment with a variety of hardware, such as K-wires [37-39], screws [40], needles [41], external fixators [42], tension wires [43] and plates $[44,45]$. Indirect methods involve reducing and fixing the displaced bone without going through the osteotendinous lesion. The main techniques are trans-articular DIPJ pinning and the Ishiguro method [6]. The main drawbacks of indirect techniques are short-term stiffness and septic arthritis and longterm osteoarthritis. Some authors combine these techniques by performing a trans-osseous suture protected by a trans-articular DIPJ wire and/or a splint until the hardware is removed $[37,38]$.

\section{Comparing Splinting to Operative Treatment}

There were some reviews comparing non-operative and operative treatments. Wehbe et al. [21] retrospectively reviewed 160 patients with mallet injuries; including 44 with avulsion fractures (28\%). Degenerative changes were comparable in both operative and non-operative groups thus splinting was reported as a safe and reliable treatment for most mallet injuries. they concluded in their review that most mallet fractures can be treated conservatively, ignoring joint subluxation and the size and amount of displacement of the bone fragment since surgical treatment was difficult and unreliable. Lubahn [4] compared open and closed techniques for treatment of mallet finger fractures and concluded that anatomical restoration of the joint by open treatment provided a cosmetically and functionally better result. Auchincloss [46] prospectively randomized 50 consecutive patients with mallet injuries to either closed pinning or splint treatment. There were three skin irritations with splinting and two pin track infections. The results were comparable for surgical and nonsurgical treatment, but from the results, patients treated in the second week after injury would do better with surgery.

Niechajev [47] performed a ten-year non-randomized prospective cohort study involving 150 patients with mallet finger injuries. Eighty-two patients had tendon injuries and 68 had avulsion fractures. Non-surgical treatment consisted of an aluminium splint either placed dorsally or volarly and surgery was performed by pinning and open repair of the fracture with a pull-out wire technique. The results suggested that surgery should be considered for injuries with subluxation of the distal phalanx and small fragments including more than a third of the joint surface and with a diastasis larger than $3 \mathrm{~mm}$. Stern and Kastrup [48] reviewed 123 mallet injuries retrospectively. Among these injuries, there were 45 intra-articular fractures, 37 avulsion fractures and 39 tendon injuries. Seventy-eight patients were treated with splints, 39 with surgery and six with both. There was a complication rate of $53 \%$ in the surgically treated patients including infections (20\%), permanent nail deformities (18\%), joint incongruity (18\%), fixation failure $13 \%)$ and bony prominence (11\%) [68]. In this study, splinting was the preferred treatment.

Geyman et al. [49] provided a meta-analysis of studies published from 1966 through 1998 but found only one randomized clinical trial. It was concluded that splint treatment was acceptable for most mallet injuries including fractures up to one-third of the articular surface. Extensor lag up to $30 \%$ was well tolerated in most patients, and surgery should be used in complex or recurrent injuries. A more recent meta-analysis by Handoll \& Voghela [20] identified 4 articles that met the inclusion criteria: three involving splint treatment and one comparing splinting and K-wire fixation. Despite this study, there was insufficient evidence to determine which splint type was the best. Splinting must however be strong enough to withstand everyday use and, strict adherence to the protocol is necessary. Concerning operative treatment, there was insufficient evidence to determine when it is indicated. 


\section{Indications and Contraindications of Surgical} Treatment

Most authors agree regarding the indications for the treatment of closed mallet finger lesions in adults but advocate a variety of treatment techniques. The classification of the lesion is the most important deciding factor. Patient history (including compliance and occupation), the time elapsed since the initial trauma, and the degree of the extension deficit also enter consideration [50]. No therapeutic consensus exists. In the literature, specific indications are described, but no decision algorithm is given. For example, some authors have proposed that health professionals should always undergo surgical treatment in order to minimize time off the job, while others have suggested that wearing a glued splint on the nail leaves the pulp free to be used, enabling the patient to continue working $[15,51]$. Most authors have described treating tendinous mallet fingers conservatively, except for one researcher who reported treating them surgically with a direct suture and trans-articular DIPJ pinning [25].

Regarding bony mallet fingers, some only consider the amount of fractured articular surface without considering the presence of DIPJ subluxation when offering surgical treatment. The threshold varies among authors, ranging from above one third $[37,38]$ to above $48 \%$ [24] or above two thirds [21] of the articular surface. Others have considered the presence of irreducible subluxation despite proper splinting, not considering the fractured articular surface when offering surgical treatment $[28,52]$. Some authors have argued that no indications for surgical treatment exist [20]. Factors making patient compliance extremely unlikely (e.g., Alzheimer disease, dementia, or major psychiatric disorders) is a relative contraindication for conservative treatment [50].

\section{Complications of treatment for Mallet Fractures}

Both non-operatively and operatively treated mallet fingers were reported to have complications related to the treatment methods. Stern et al. [48] reviewed the complications of treatment in 123 mallet fingers. Complications of splinting include dorsal ulceration, skin maceration and nail deformities such as transverse groove in the fingernail which were found in $45 \%$ of patients in one study. The complication rate was noted to be $53 \%$ in 45 surgically treated digits which included deep infection, joint incongruity and nail deformity with $76 \%$ of the complications still present after a long period of followup. A retrospective review by Kang et al. [53] revealed $41 \%$ postoperative complication rate among 59 surgically treated mallet fractures. He found that marginal skin necrosis on the dorsal aspect of the distal phalanx was the most common complication. Other complications include residual extension lag, permanent nail deformities, transient infections along the Kirschner wire and pull-out wire tracks and osteomyelitis.

\section{Conclusion}

Operative treatment of mallet fractures can prevent residual complications of splinting as stiffness, limited range of flexion, extension lag and swan neck deformity. It is indicated in cases of palmer subluxation of the distal interphalangeal joint and articular surface affection more than one third of the distal phalanx. Type of operative treatment depends on patient compliance and surgeon preference.

\section{References}

1. McCue FC $3^{\text {rd }}$, Meister K (1993) Common sports hand injuries. An overview of aetiology, management and prevention. Sports medicine, Auckland, New Zealand 15(4): 281-289.

2. Schweitzer TP, Rayan GM (2004) The terminal tendon of the digital extensor mechanism: Part II, kinematic study. J Hand Surg Am 29(5): 903-908.

3. Damron TA, Engber WD, Lange RH, McCabe R, Damron LA, et al. (1993) Biomechanical analysis of mallet finger fracture fixation techniques. J Hand Surg Am 18(4): 600-607.

4. Lubahn JD (1989) Mallet finger fractures: a comparison of open and closed technique. J Hand Surg Am14(2 Pt 2): 394-396.

5. Hamas RS, Horrell ED, Pierret GP (1978) Treatment of mallet finger due to intra-articular fracture of the distal phalanx. J Hand Surg Am 3(4): 361-363.

6. Ishiguro T, Itoh Y, Yabe Y, Hashizume N (1997) Extension block with Kirschner wire for fracture dislocation of the distal interphalangeal joint. Tech Hand Up Extrem Surg 1(2): 95-102.

7. Takami H, Takahashi S, Ando M (2000) Operative treatment of mallet finger due to intra-articular fracture of the distal phalanx. Arch Orthop Trauma Surg.120(1): 9-13.

8. Kronlage SC, Faust D (2004) Open reduction and screw fixation of mallet fractures. J Hand Surg Br 29(2): 135-138.

9. Tetik C, Gudemez E (2002) Modification of the extension block Kirschner wire technique for mallet fractures. Clin Orthop Relat Res 2002(404): 284-290.

10. Bachoura A, Ferikes AJ, Lubahn JD (2017) A review of mallet finger and jersey finger injuries in the athlete. Curr Rev Musculoskelet Med 10(1): 1-9.

11. Lubahn JD, Hood JM (1996) Fractures of the distal interphalangeal joint. Clin Orthop Relat Res 1996(327): 12-20.

12. Schneider LH (1994) Fractures of the distal interphalangeal joint. Hand Clin 10(2): 277-285.

13. Craig SM (1992) Anatomy of the joints of the fingers. Hand Clin 8(4): 693-700.

14. Verdan C (1964) practical considerations for primary and secondary repair in flexor tendon injuries. The Surgical clinics of North America 44: 951-970.

15. Clayton RA, Court-Brown CM (2008) The epidemiology of musculoskeletal tendinous and ligamentous injuries. Injury 39(12): 13381344.

16. de Jong JP, Nguyen JT, Sonnema AJ, Nguyen EC, Amadio PC, et al. (2014) The incidence of acute traumatic tendon injuries in the hand and wrist: a 10-year population-based study. Clin Orthop Surg 6(2): 196-202.

17. Stark HH, Boyes JH, Wilson JN (1962) Mallet finger. J Bone Joint Surg Am 44-a:1061-1068. 
18. Lange RH, Engber WD (1983) Hyperextension mallet finger. Orthopedics 6(11): 1426-1431.

19. Zancolli E (1968) Structural and dynamic bases of hand surgery. Lippincott, Philadelphia, USA.

20. Handoll HH, Vaghela MV (2004) Interventions for treating mallet finger injuries. Cochrane Database Syst Rev 2004(3): Cd004574.

21. Wehbé MA, Schneider L (1984) Mallet fractures. J Bone Joint Surg Am 66(5): 658-659.

22. Tubiana R (1986) Mallet finger. In: Tubiana R eTdcdlmPNYMp. Mallet finger. Traite de chirurgie de la main. (Traite de chirurgie de la main. Paris; Masson, New York, USA, pp.109-121.

23. Doyle J (1993) Extensor tendons: acute injuries $3^{\text {rd }}$ ed. DP G, (ed), Churchill Livingstone, Churchill Livingstone, New York, USA, p. 26 .

24. Kim JK, Kim DJ (2015) The risk factors associated with subluxation of the distal interphalangeal joint in mallet fracture. J Hand Surg Eur Vol 40(1): 63-67.

25. Lu J, Jiang J, Xu L, Xu W, Xu J (2013) Modification of the pull-in suture technique for mallet finger. Ann Plast Surg 70(1): 30-33.

26. Katzman BM, Klein DM, Mesa J, Geller J, Caligiuri DA (1999) Immobilization of the mallet finger. Effects on the extensor tendon. J Hand Surg Br 24(1): 80-84.

27. Abouna J, Brown H (1968) The treatment of mallet finger the results in a series of 148 consecutive cases and a review of the literature. $\mathrm{Br}$ Surg 55(9): 653-667.

28. Facca S, Nonnenmacher J, Liverneaux P (2007) Treatment of mallet finger with dorsal nail glued splint: retrospective analysis of 270 cases. Rev Chir Orthop Reparatrice Appar Mot 93(7): 682-689.

29. Devan D (2014) A novel way of treating mallet finger injuries. Journal of hand therapy: official journal of the American Society of Hand Therapists 27(4): 325-328.

30. O’Brien LJ, Bailey MJ (2011) Single blind, prospective, randomized controlled trial comparing dorsal aluminum and custom thermoplastic splints to stack splint for acute mallet finger. Archives of physical medicine and rehabilitation 92(2): 191-198.

31. Smit JM, Beets MR, Zeebregts CJ, Rood A, Welters CF (2010) Treatment options for mallet finger: a review. Plast Reconstr Surg 126(5): 16241629.

32. Hart RG, Kleinert HE, Lyons K (2005) The Kleinert modified dorsal finger splint for mallet finger fracture. The American journal of emergency medicine 23(2): 145-148.

33. Stack G (1968) Mallet finger. Lancet, London, England 2(7581): 1303.

34. Valdes K, Naughton N, Algar L (2015) Conservative treatment of mallet finger: A systematic review. J Hand Ther 28(3): 237-245.

35. Gruber JS, Bot AG, Ring D (2014) A prospective randomized controlled trial comparing night splinting with no splinting after treatment of mallet finger. Hand (N Y) 9(2):145-150.
36. Pratt DR, Bunnell S, Howard LD, Jr (1957) Mallet finger; classification and methods of treatment. Am J Surg 93(4): 573-578.

37. Chung DW, Lee JH (2012) Anatomic reduction of mallet fractures using extension block and additional intrafocal pinning techniques. Clin Orthop Surg 4(1): 72-76.

38. Lee YH, Kim JY, Chung MS, Baek GH, Gong HS, et al. (2009) Two extension block Kirschner wire technique for mallet finger fractures. J Bone Joint Surg Br 91(11): 1478-1481.

39. Pegoli L, Toh S, Arai K, Fukuda A, Nishikawa S, et al. (2003) The Ishiguro extension block technique for the treatment of mallet finger fracture: indications and clinical results. J Hand Surg Br 28(1): 15-17.

40. Shimura H, Wakabayashi Y, Nimura A (2014) A novel closed reduction with extension block and flexion block using Kirschner wires and microscrew fixation for mallet fractures. J Orthop Sci 19(2): 308-312.

41. Miranda BH, Murugesan L, Grobbelaar AO, Jemec B (2015) PBNR: Percutaneous Blunt Needle Reduction of Bony Mallet Injuries. Tech Hand Up Extrem Surg 19(2): 81-83.

42. Miura T (2013) Extension block pinning using a small external fixator for mallet finger fractures. J Hand Surg Am 38(12): 2348-2352.

43. Kakinoki R, Ohta S, Noguchi T, Kaizawa Y, Itoh H, et al. (2013) A modified tension band wiring technique for treatment of the bony mallet finger. Hand Surg 18(2): 235-242.

44. Teoh LC, Lee JY (2007) Mallet fractures: a novel approach to internal fixation using a hook plate. J Hand Surg Eur Vol 32(1): 24-30.

45. Acar MA, Guzel Y, Gulec A, Uzer G, Elmadag M (2015) Clinical comparison of hook plate fixation versus extension block pinning for bony mallet finger: a retrospective comparison study. J Hand Surg Eur 40(8): 832-839.

46. Auchincloss JM (1982) Mallet-finger injuries: a prospective, controlled trial of internal and external splintage. The Hand 14(2): 168-173.

47. Niechajev IA (1985) Conservative and operative treatment of mallet finger. Plast Reconstr Surg 76(4): 580-585.

48. Stern PJ, Kastrup JJ (1988) Complications and prognosis of treatment of mallet finger. J Hand Surg Am 13(3): 329-334.

49. Geyman JP, Fink K, Sullivan SD (1998) Conservative versus surgical treatment of mallet finger: a pooled quantitative literature evaluation. J Am Board Fam Pract 11(5): 382-390.

50. Salazar Botero S, Hidalgo Diaz JJ, Benaida A, Collon S, Facca S, et al. (2016) Review of Acute Traumatic Closed Mallet Finger Injuries in Adults. Arch Plast Surg 43(2): 134-144.

51. Chauhan A, Jacobs B, Andoga A, Baratz ME (2014) Extensor tendon injuries in athletes. Sports Med Arthrosc Rev 22(1): 45-55.

52. Nakamura K, Nanjyo B (1994) Reassessment of surgery for mallet finger. Plast Reconstr Surg. 93(1): 141-149.

53. King HJ, Shin SJ, Kang ES (2001) Complications of operative treatment for mallet fractures of the distal phalanx. J Hand Surg Br 26(1): 28-31. 
This work is licensed under Creative Commons Attribution 4.0 License DOI: 10.19080/OROAJ.2019.15.555904
Your next submission with Juniper Publishers will reach you the below assets

- Quality Editorial service

- Swift Peer Review

- Reprints availability

- E-prints Service

- Manuscript Podcast for convenient understanding

- Global attainment for your research

- Manuscript accessibility in different formats ( Pdf, E-pub, Full Text, Audio)

- Unceasing customer service

Track the below URL for one-step submission https://juniperpublishers.com/online-submission.php 